\title{
GENERAL CONSIDERATIONS ABOUT THE REVISION OF ALL THE CALCULATIONS OF THE INTERNATIONAL

\author{
LATITUDE SERVICE
}

\author{
P. MELCHIOR, R. DEJAIFFE, and R. VERBEIREN \\ Observatoire Royal de Belgique
}

\begin{abstract}
A general revision of the calculations of the ILS is necessary, for several reasons. The first fundamental step has been performed with the Melchior-Dejaiffe catalogue. From it, improved values of the screw pitches and their adjustments, new investigations upon closing errors in all the ILS stations with introduction of the tidal deflection of the vertical, new deduction of the Kimura $z$-term and definitive calculations of $x, y, z$ are obtainable.
\end{abstract}

\section{Declination and Proper Motion System}

Investigations independently made by Wako and by Fichera have shown that the Melchior-Dejaiffe catalogue (1969) of latitude stars-declinations and proper motions is presently the best system as it is quite homogeneous for all the stars of the different programs introduced since 1899 .

It should be the basic system for the new reduction of data.

\section{Reduction to Apparent Places}

The method of Dufour and Fontaine (1959), introduced for satellite plates measurements and using only rotations of axes, is to be recommended as it is the most convenient with computers, faster and more precise if completely used in double precision. It avoids handling of all the Bessel numbers.

\section{Fundamental Constants and Closing Error}

The fundamental constants of the IAU should be used.

The main improvement will be in the constant of aberration. The closing errors are to be analysed carefully after this new reduction in order to try to determine the real origin of the remaining part of it. Therefore we recommend that the tidal deflection of the vertical will be introduced with a value of the coefficient $1+k-l=1,20$.

Modern recent measurements of Earth Tides proves that such a value is sufficiently exact for latitude reduction (Melchior, 1970a).

The results will be fundamental for a new discussion of nutation constants in view of the resonance effects of the liquid Earth core (Melchior, 1970b). Most important in this respect are eight pairs continuously maintained in all programs, during more than $70 \mathrm{yr}$. These pairs are evidently centered on 6 and $18 \mathrm{hr}$ right ascension as the 


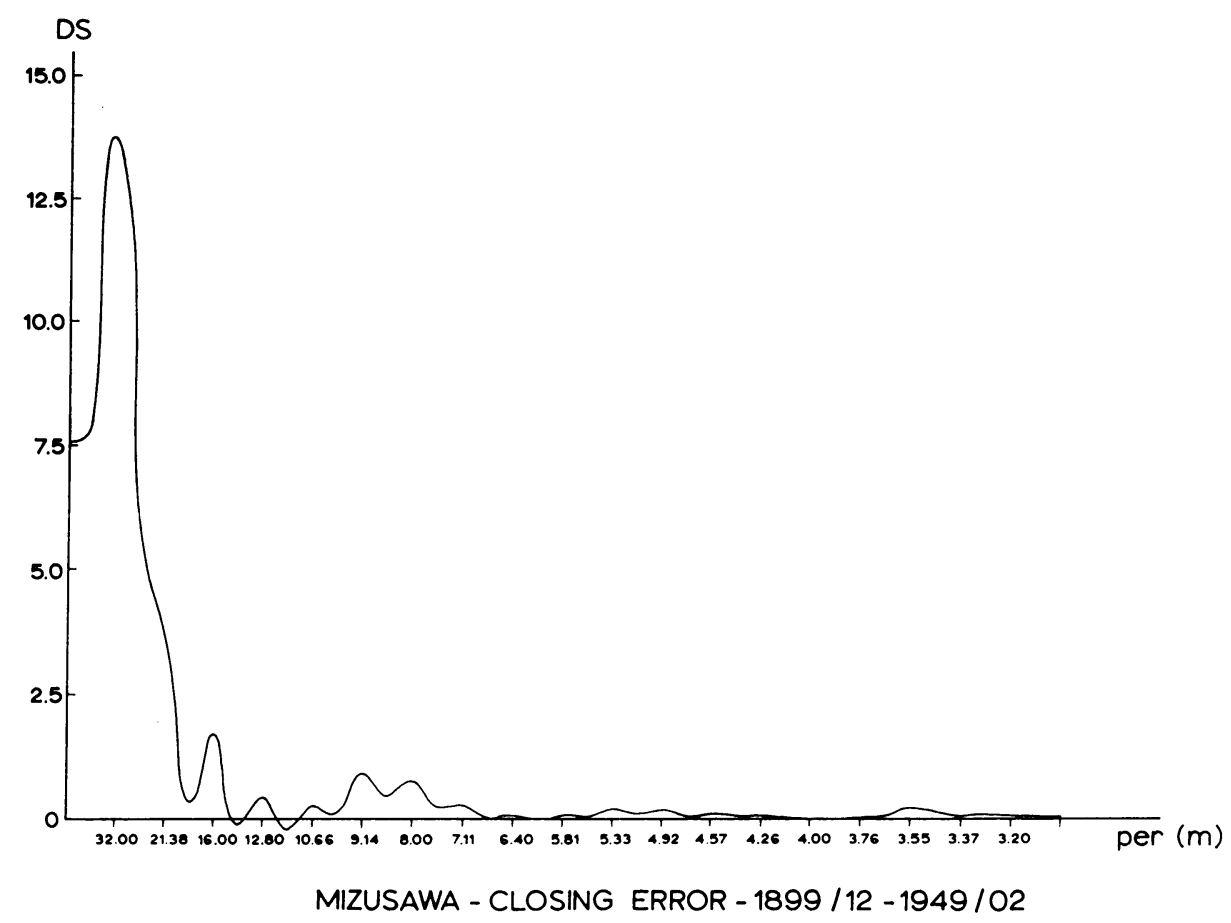

Fig. 1.

rejection of pairs from the programs is due to precession effect in declination. This effect is zero for these hours.

A first tentative is just undertaken, from all yet published information, to investigate the closing error in each station. A classical method (Dejaiffe, 1970) of spectral analysis is used to search for eventual periodicities in this kind of error. Actually, the following continuous periods were analyzed: Mizusawa (from 1899/12 till 1949/02), (Figure 1), Carloforte (1899/10 till 1927/06), Ukiah (1899/10 till 1946/10) and Kitab (1931/10 till 1948/12); and the following results were derived, with some consideration.

In Mizusawa, it seems quite evident that we have found a periodicity of about $32-34$ months in the closing error; periodicities with smaller amplitudes $(10 \%$ of the 32-months amplitude) seem also be effective for 15-17 months and 8-10 months. The enclosed figure presents these Mizusawa results.

The 32-months period is probably correlated with the similar period found by Sugawa (1969) in the periodogram analysis of air temperature at Mizusawa; the 15-17 months period is perhaps correlated with the variation of barometric pressure as pointed out by Hosoyama and Sato (1969) for the Chandlerian periodicity. The predominant 32-34 months period can also perhaps be correlated with the similar period found by King-Hele and Walker in the air density at a height of $470 \mathrm{~km}$ from the orbit of the satellite 1966-118 A.

In Carloforte ILS station, much less evident periodicities appear for periods of 8-9 
months and 4-5 months, and signification tests will be certainly necessary to confirm or invalidate these results.

Analysis of Ukiah closing errors are more difficult. Periodicities of 26-30, 7, 5-9, 4-5 and 3, 25 months seem to be present.

Finally, the continental Kitab station gives quite a certain periodicity between 24 and 29 months, and an eventual one between 8 and 9 months. The amplitude of the principal 24-29 months periodicity is $0.15 \pm 0$ ".03. This periodicity is perhaps the 2.113-yr one mentioned by Lange (1950) in the Astronomiceskii Cirkuljar. Contrarily to Korsoun's paper (1961), rejecting Lange's result, it seems well that such periodicities, for Kitab or other ILS stations, are significative and that the apparent periodicity, different for each station, not exclusively comes from the influence of random deviations smoothing.

These analysis evidently will be continued, extended and completed.

\section{Screw Pitches}

One knows that screw pitch errors produce a spurious annual component in the polar motion.

But the screw pitches were adjusted with the relation

$$
\Delta \Phi=\Delta \delta+\Delta R\left(M_{\mathrm{E}}-M_{\mathrm{W}}\right)
$$

which involves at the same time the declination corrections of the 2 stars of the pair.

It is clear that when starting such computations with big $\delta$ errors, the correction of the screw pitch is not surely determined.

Here again we shall have great advantages when performing those computations with better $\delta$ values involving only a possible little $\Delta \delta$ correction.

The improvement of screw pitches is essential for the characteristics of the annual geophysical component of polar motion.

\section{Conventional International Origin (C.I.O.)}

We have no explanation of the drift of the mean pole. Some linear part of it is due to the ice caps, their melting and their distribution. Some part may be ascribed to a long period effect, while an other part is related to star places errors.

Thus the elimination of the drift cannot be made by one or another filtering process. Mathematical properties of these filters even show that spurious effects may be introduced.

Then, the only way to do so is to fix a conventional origin just as the IAU did it at its Prague meeting. So the possibility is left to everybody to make any combination with polar coordinates starting from non traficated data. A pecular example can be given.

The $x, y$ pole coordinates (1900-1970) with respect to CIO were given by our colleagues Yumi and Vicente. A similar set is published by the Annuaire du Bureau 
des Longitudes 1971 . They are not the same! Besides we have the coordinates proposed by our colleague Proverbio.

Based upon such tables geophysicists apply the most sophisticated mathematical methods of analysis to get geophysical parameters as free periods and relaxation times and obtain quite different results of course.

We think this procedure must be stopped until we have a definitive system of coordinates correctly calculated from the original rereduced data. It is also very important to refer $(x, y)$ coordinates to the CIO because the Standard Earth has its reference axis related to CIO.

As it seems possible now to derive the position of the pole of inertia from satellite orbit perturbations (through $C_{21}, S_{21}$ coefficient of the Standard Earth potential) as well as the position of the instantaneous pole of rotation (through kinematic effects) it is essential and of fundamental interest that everybody uses CIO as unique reference.

\section{6. $Z$-term}

Using the Melchior-Dejaiffe catalogue, the new aberration constant and improved screw pitches, important parts of this term will disappear. Thus it will be easier to analyse the remaining components and to try to find the geophysical origin of it.

\section{Determination of Coordinates and Drawing of the Polhody}

For each station, latitude values are to be deduced in the form of monthly group means. Then the coordinates $x, y$ and $z$ for the corresponding epochs are to be derived by mean squares.

Interpolated coordinates such as coordinates given for each tenths of a year can be given if one applies the following procedure:

(a) To determine for each station a smoothed variation latitude curve by polynomial fitting (orthogonal polynomial) or, better, Vondrak procedure on a set of 5 or 6 months (Honorez, 1971).

(b) To calculate on the such obtained 5 curves the instantaneous latitude for every 5 or 10 days.

(c) To calculate $(x, y, z)$ from these smoothed data and tracing of the polhody.

The drawings given in some publications are made by hand smoothing between each tenth of a year, or worse by straight lines joining the individual points.

Both methods must be rejected.

\section{References}

Dejaiffe, R. J.: 1970, Astron. Astrophys. 7, 169.

Dufour, H.-M. and Fontaine, A.: 1961, Bull. Astron. 23, 117.

Honorez, M.: 1971, Contribution à l'étude des méthodes de lissage des observations, Louvain, mémoire.

Hosoyama, K. and Sato, N.: 1969, Proc. Int. Lat. Obs. Mizusawa 9, 38.

Корсунь, А. А.: 1961, Исследование изменений ощибок замыкания - УІІІ Раздел Програм. МГГ - Щиротн и Долготы - Изд. АН СССР Москва - Стр. 92-97. 
Ланге, Г. А.: 1950, Об ощибке замыкания в щиротных наблюдениях. Астр. Циркул. Соодщен. АН СССР № 108 Дек. 27. Стр. 7-8.

Melchior, P.: 1970a, Rapport du Directeur du Centre International des Marées Terrestres. Sixième Symposium International sur les marées terrestres, Obs. Roy. de Belgique, Comm. série A No. 9. série Géophys. No. 96.

Melchior, P.: 1970b, in 'System of Astronomical Constants', IAU Colloquium, No. 9, Heidelberg

Melchior, P. and Dejaiffe, R.: 1969, Ann. Obs. Roy. Belgique X, No. 3.

Sugawa, Ch.: 1969, Proc. Int. Lat. Obs. Mizusawa 9, 30.

\section{DISCUSSION}

B. Guinot: (1) I remark that the existence of breaks or discontinuities in the UT1 measurements make it impossible to use an appropriate smoothing technique and emphasizes the need for publishing new data. (2) I ask Melchior what are his recommendations about the diurnal nutation terms (Oppolzer terms) and the personal errors?

P. Melchior: (1) If one has proof that there is a real discontinuity in the data, smoothing is evidently not allowed and one must introduce a jump in the results. (2) For the diurnal terms of forced nutation with respect to the Earth, I should recommend the use of amplitudes derived for a rigid Earth corresponding to the amplitudes of short nutation terms in space. Both developments must indeed be taken for the same model of Earth's interior. We do not know anything about personal errors in the international stations. As the name of each observer is now introduced in the punched cards for the $\mathbf{7 0} \mathrm{yr}$ of observations, it should be possible to make some investigations about this in the future.

E. P. Fedorov: Have all the points been taken with equal weight? If the number of individual observation forming normal values is not the same, which weights should be ascribed to these normal values?

P. Melchior: In the given example, all the points are individual measurements of equal weight. The method allows us to introduce different weights. We could adopt weights proportional to the square root of the number of observations or derived from the mean square error of each value.

E. P. Fedorov: Dr. Yatskiv has recently considered a problem of weights in the case when observational errors are not independent values.

S. Débarbat: A remark about the discussion between Fedorov and Melchior about smoothing. Something was said about the number of observations and the system of weighting. My feeling is that it is a question of the results we want.

$P$. Melchior: One can try to apply different systems of weight. The degree of smoothing depends upon the numerical value given to the $\lambda$ parameter.

G. Teleki: (1) The level error is also important. (2) I want to stress the importance of investigations on the local refractional effects.

$P$. Melchior: I completely agree about this opinion. However I do not see how we could improve level data given in the observation books. All we can do is to check the bubble lengths. Local refraction effects depend upon micrometeorology. Systematic differences between the different stations are shown by the spectral analysis of closing errors.

S. Yumi: Dr. Teleki appears to have asked about the level error. Level error is mainly caused by the method of observation. If the bubble position is the same for each star forming a pair, there might be no level error. There might, however, be errors caused by friction in level vials. This kind of error is accidental.

G. Teleki: Connected with levels we have two problems: how to obtain the real level constants, and how to protect levels from temperature influences. These temperature influences play an important role, and have perhaps, a yearly systematic period. 